Accepted for publication in the International Journal of Pest Management 51(4): 305 312.

\title{
Damage potential of two Scarab species on groundnut.
}

D.JOHN. ROGERS ${ }^{1}$, ANDREW.L. WARD $^{2}$, and JOHN.A. WIGHTMAN ${ }^{3}$

${ }^{1}$ Farming Systems Institute, Indooroopilly Sciences Centre, Queensland Department of Primary Industries, 80 Meiers Rd, Indooroopilly 4068, Australia. Present address:

Research Connections and Consulting, PO Box 350, Toowong, Queensland 4066, Australia

${ }^{2}$ Queensland Department of Primary Industries, P O Box 23, Kingaroy, Qld 4068.

Present address: BeckerUnderwood Australia, RMB 1084, Pacific Highway, Somersby, New South Wales 2250, Australia.

${ }^{3}$ International Pest Management, Conondale Cottage, 931 Stanley River Rd. Maleny, Queensland 4552, Australia

Word count: Abstract - 169 words, Main text (including references) - 4220 words. 


\begin{abstract}
The damage potential of two phytophagous scarab larvae on groundnut (peanut) yield was determined. Holotrichia serrata, a root and pod feeding species from southern India, was studied in microplots while the damage potential of Heteronyx piceus, a pod feeder from Queensland, Australia, was determined by analysis of on-farm chemical-rate trials. H. serrata larva reduced groundnut yield by an average of $7.52 \mathrm{~g} /$ larva. In crops yielding less and more than $1900 \mathrm{~kg} \mathrm{ha}^{-1}, H$. piceus reduced yield by 4.20 $\mathrm{g}$ and $1.43 \mathrm{~g} /$ larva, respectively. These damage potential estimates were used to determine provisional economic injury levels (EIL). For H. piceus, the provisional EIL is 1.67 and 4.91 larvae/ row-metre in crops yielding less and more than $1900 \mathrm{~kg} / \mathrm{ha}$, respectively. For $H$. serrata, the provisional EIL is one $H$. serrata larva in $7.1 \mathrm{~m}^{2}$. As more than $70 \%$ of southern India groundnut fields have Holotrichia populations greater than 1 larva in $1.35 \mathrm{~m}^{2}$, more widespread use of chlorpyrifos seed dressing of groundnut is likely to produce regional economic benefits.
\end{abstract}


Keywords: Heteronyx piceus, Holotrichia serrata, Coleoptera, Scarabaeidae, yield loss, peanut, economic injury level

Correspondence: D. John Rogers, Research Connections and Consulting, PO Box 350, Toowong, Queensland 4066, Australia. Fax: +61 73720 9065. Email:

john.rogers@rcac.net.au 


\section{Introduction}

White grubs, the larvae of Scarabaeid beetles, are major pests of groundnut (peanut) in many parts of the world (Wightman and Ranga Rao, 1994), feeding on both roots and pods. For root-feeding species, moisture stress and death of attacked plants commonly results (Wightman et al., 1994), with consequent negative impact on crop yield. Pod feeders directly consume pods without killing plants or inducing apparent moisture stress, but still have significant effects on crop yield (Rogers and Brier, 1992).

However, quantitative data on the damage potential of white grubs in groundnut is generally lacking, even though the effects on plant growth are often clear in the field (Wightman and Wightman, 1994; Yadava and Sharma, 1995). Estimates of the damage potential of white grubs provides the basis for determining the pest status of a species; such estimates allow the determination of population levels that warrant active management intervention, while combining damage potential data with field data on population densities can lead to estimates of industry-wide losses.

Here we present quantitative data on the damage potential of two species of white grub in groundnut. These species are the root and pod feeder Holotrichia serrata Hope from southern India, and the pod-feeder Heteronyx piceus Blanchard from Queensland, Australia. The data on the $H$. serrata comes from studies of plant yield in infested microplots, while the H. piceus relationships were derived from analysis of a series of onfarm chemical screening experiments. 


\section{Materials and methods}

\subsection{Heteronyx piceus}

A series of seven experiments were conducted in the South Burnett region of Queensland, Australia, between 1984 and 1988 to evaluate rates of carbofuran for control of $H$. piceus; data from six of these trials has been reported previously from the perspective of chemical efficacy (Brier, 1989), but did not estimate the damage potential of $H$. piceus. Here we look in detail at the yield/ pest density relationships using data from the original six trials, plus data from an additional trial done in $1987 / 88$.

Experimental methods were reported in detail in Brier (1989) and are summarised here. All experiments were conducted on farms infested with H. piceus larvae in the South Burnett region, Queensland, using groundnut grown in $91 \mathrm{~cm}$ rows under normal commercial agronomic regimes. A range of $H$. piceus larval densities was achieved by applying a range of insecticide dose rates in experiments laid out in randomised-block designs with four replications of each treatment. In the first six trials, carbofuran (as a 10G formulation) was applied as at-planting surface-incorporated $35-\mathrm{cm}$ bands over the crop row at rates between 0.25 and $2.0 \mathrm{~kg}$ a.c./ ha. In the final $1987 / 88$ trial, carbofuran was applied as either in-furrow treatments, at-planting bands or 3-week post-planting bands at rates to $1.0 \mathrm{~kg}$ a.c./ ha. Plot size was 4-rows x $10-\mathrm{m}$ in trials $2-6$, with $20-\mathrm{m}$ and 15-m plots being used in trials 1 and 7, respectively. In all trials, six 0.5-m samples from the centre two rows of each plot were assessed for larval density and pod damage at crop maturity. Crop yield data was collected from the remainder of the datum rows. To achieve even plant stands, and thus more precise crop-yield estimates, all trials were over- 
planted by $30-50 \%$ and thinned at the end of seedling emergence back to an uniform plant density ( 6 plants/ row-m) of evenly spaced plants. Data was analysed by linear regression using GenStat V7.2. To test hypotheses regarding equality of regression slopes and intercepts, a series of group regression analyses were conducted for the crop yield, and damaged (i.e. holed) and total pods/ row-metre data.

One site (Site 3) was excluded from the analyses of yield/ pest density relationships because the range of $H$. piceus larval density at this site (93\% of plots with fewer than 6 larvae/ row-m)was insufficient to show any relationship between pest density and crop yield. The other six sites recorded maximum larval densities of between 8.33 and 33.0 larvae/row-metre, and at least $17 \%$ of plots had greater than 6 larvae/row-m.

\subsection{Holotrichia serrata}

These experiments were conducted in small plots at ICRISAT Asia Centre, Patancheru, Andhra Pradesh, India in 1999 and 2000. The microplots were constructed of paving slabs sunk vertically in the soil. Plots were $0.5 \mathrm{~m}$ deep and 0.9 x $1.0 \mathrm{~m}$ and were filled with sandy alfisol soil. Each microplot had $2 \mathrm{~mm}$ wire mesh in bottom to prevent larvae digging below $0.5 \mathrm{~m}$ at the conclusion of feeding, which is typical larval behaviour prior to pupation (Yadava and Sharma, 1995). Normal agronomic practices were followed during crop growth. Supplementary irrigation was applied to prevent very severe water stress and plant death when there were two weeks with no significant rainfall. The high yielding, locally-adapted variety ICGS 44 was sown in all experiments. 
(insert table 1 near here)

In all trials, $H$. serrata larvae were early instar 2 when introduced into the microplots, typically in the size range $100-300 \mathrm{mg}$ (Table 1). From the infestation date, plant mortality was assessed weekly. Some replicates were destructively sampled between 21 - 33 days after larvae were introduced to estimate larval establishment and survival. Plots were excavated to $50 \mathrm{~cm}$ at crop maturity and surviving larvae collected and plant data recorded, including pod yield, root weight, plant weight and the number of pods damaged by white grubs.

The experiments were laid out as completely randomised designs. In 1999, the treatments included $H$. serrata rates of 0 and 10 larvae/ plot that also had farmyard manure (FYM) added immediately before sowing at the rate of $5,000 \mathrm{~kg} \mathrm{ha}^{-1}$. However, analysis of yield data indicated that the addition of FYM did not have a significant effect on pod yield $(\mathrm{P}>0.05)$. Consequently, the data from the FYM and standard plots were combined for the linear regression analysis using GenStat V7.2 to determine the impact of $H$. serrata populations on yield parameters.

\section{Results}

\subsection{Heteronyx piceus}

(insert table 2 near here) 
There was no relationship with H. piceus density and total pods numbers for six of the seven trials (Table 2). This is not surprising given the nature of the larval feeding (Crosthwaite, 1994, p.62 and plate 31). First instar larvae feed on soil organic matter and living plant material (most likely small roots) (Ward and Rogers, in press) while second and third instar larvae feed on pegs (incipient pods) and pods. While pegs can be chewed off, these would normally be replaced as the groundnut plant produces $5-7$ times as many flowers as mature pods, and flowering can extend over 4 to 5 weeks (Crosthwaite, 1994, p.6). This compensation response would lead to there being no reduction in total pods under the conditions typically experienced by dryland groundnut crops in the South Burnett.

One scenario which could lead to reduced pod numbers is where pod development and replacement is inhibited. Site 7 appears to be one such case. After favourable conditions up to and including peak flowering (35 - 60 days after sowing (d.a.s.)), no useful rainfall was recorded for 5 weeks at Site 3, at a time when pegs should have been developing into pods. However the dry soil would have reduced the capacity of pegs to develop into pods, as this depends on adequate soil moisture (Crosthwaite 1994). The rapidly developing second instar larvae - in their preferred location under the crop row at $5-15 \mathrm{~cm}$ depth - would have had been in an ideal position to feed on the pegs sitting undeveloped in the dry soil. While useful rainfall in early to mid-February would have promoted additional flowering and pegging, the subsequent 7 week dry period would have prevented any new pegs developing into pods, leaving them susceptible to attack by the third instar larvae. 
If this shift towards increased feeding on pegs did occur at this site, then a compensatory reduction in the damage rate of pods would be expected. This was, in fact, detected at Site 7; the slope of the regression line for holed pods was significantly lower $(\mathrm{P}<0.01)$ for Site 7 (slope $=1.1618, \mathrm{SE}=0.127)$ than for all other sites (range 1.5988 - 3.2658). The other six experiments with $H$. piceus indicate that under a wide range of conditions, $H$. piceus infestation does not reduce total pod numbers.

For all seven experiments, the relationship between holed pods/ row-m and H. piceus larvae/row-m went through the origin $(\mathrm{P}>0.05)$, as expected from the direct cause and effect relationship that exists between $H$. piceus larvae and holed pods. There were, however, three groups of slopes (Table 2). Site 7 had the lowest slope, for reasons previously discussed. The other two groups of sites were Site $1-4$ (average slope $=$ $1.6679, \mathrm{SE}=0.0576)$ and Sites 5 and 6 (average slope $=2.8170, \mathrm{SE}=0.357)$. Sites 5 and 6 were conducted in 1986/87 and in that year, the crop duration averaged 158 days (range 156 - 160 days), compared to 145 days (range 145 - 146 days) for Sites 1 to 4. The delayed harvest at Sites 5 and 6 is most likely the reason for the greater rate of holed pods at these sites. In summary, for crops harvested after normal crop durations, the rate of pod damage from $H$. piceus averages 1.7 pods/ larvae, but this can be higher in crops where harvest is delayed.

The individual regression analyses between $H$. piceus density and crop yield showed significant negative regressions for four of the six sites (Figure 1). For Sites 2 and 6, the slopes of the fitted lines were also negative but the range of the data in these trials (Site 2: 1.3 - 19.3 larvae/ row-m, Site 6: 1.7 - 13.0 larvae/row-m) was insufficient 
compared to Site $1(0.3-33.0$ larvae/row-m) for the small negative slope to be statistically different from 0 .

The group regression analyses provided greater statistical power and showed that the six trials fell into two groups that were statistically different $(\mathrm{P}<001)$, but consistent within $(\mathrm{P}>0.05$ for both groups). This indicates that within each group, the regression lines had a common slope. Sites 1, 2 and 6 (called Group 1 from here on) had a significant negative relationship between yield and pest density, with average slope of $15.7 \mathrm{~kg} / \mathrm{ha}(\mathrm{SE}=3.9 \mathrm{~kg} / \mathrm{ha})(\mathrm{P}<0.001)$, but with different intercepts (i.e. crop yield differed in the absence of $H$. piceus). Sites 4, 5 and 7 (Group 2) had a significant and strongly negative relationship between yield and pest density, with a slope of -45.9 $\mathrm{kg} / \mathrm{ha}(\mathrm{SE}=6.5 \mathrm{~kg} / \mathrm{ha})(\mathrm{P}<0.001)$, and again with different intercepts.

(insert figure 1 near here)

Figure 2 plots the slope of the crop yield regression against the uninfested yield (i.e. intercept) and provides additional information about the characteristics of the two groups identified by the group regression analysis. Group 1 comprises low yielding sites with high rates of loss per white grub (Sites 4, 5 and 7, average uninfested yield = $1750 \mathrm{~kg} / \mathrm{ha}$, average loss $=45.9 \mathrm{~kg} / \mathrm{ha}$ from 1 larvae$/$ row-metre at crop maturity).

Group 2 consists of higher yielding sites with markedly lower loss per white grub (Sites 1, 2 and 6 , average uninfested yield $=2650 \mathrm{~kg} / \mathrm{ha}$, average loss $=15.7 \mathrm{~kg} / \mathrm{ha}$ from 1 larvae/row-metre). As groundnuts in the South Burnett are grown in $0.91 \mathrm{~m}$ rows, these rates of loss equate to 4.20 and $1.43 \mathrm{~g} /$ larva at crop maturity for the low-yielding and 
high-yielding sites, respectively. The most likely reason for this difference lies in the potential for plant compensation. Crops with greater yield potential (for whatever reason, but including lower moisture stress) would have greater capacity to compensate for the feeding of $H$. piceus larvae on pegs and pods, leading to lower rates of crop loss in wellgrown crops than poorer crops at the same pest population density.

(insert figure 2 near here)

\subsection{Holotrichia serrata}

Larval survival to harvest was similar in the three experiments. Sixty percent of larvae survived through to harvest following the first introduction (35 d.a.s.) in 1999, 68\% survived following the second introduction (55 d.a.s.), and $48 \%$ in 2000 . Grub survival in all three groups was slightly lower at the final harvest than at the first sampling, when $70 \%, 80 \%$, and $70 \%$ of grubs, respectively, were recovered. Our conclusion from these survival data is that most of the larvae that survived for the first few weeks after introduction then survived until crop maturity. On this basis, the larval numbers recovered at harvest better represent a plot's infestation intensity than the initial larval number. The other advantage of using final larval numbers is that these relate more closely to the developmental stage of larvae collected in regional surveys (Anitha et al., in press) than initial density; using damage potential relationships based on final larval numbers in combination with larval density data from regional surveys should enable estimation of the regional losses from $H$. serrata. 
(insert figure 3 near here)

As expected, the presence of $H$. serrata larvae reduced pod yield $(\mathrm{P}<0.001)$ (figure 3). The regressions for the two infestation dates in 1999 did not differ significantly in either slope or intercept (both $\mathrm{P}>0.05$ ). The equation for the combined 1999 data was:

$$
\mathrm{Y}=219.5-7.511 \mathrm{X}, \mathrm{F}_{1,28}=35.09, \mathrm{P}<0.001 \text {. }
$$

While the uninfested yield in 2000 was about half that of 1999 because of different seasonal conditions, the slope of the regression line in 2000 was $7.52 \mathrm{~g} /$ larva, almost identical to the pooled value for 1999 giving an average loss per $H$. serrata larva completing development of $7.52 \mathrm{~g}$ over the two years of trials.

(insert table 3 near here)

For all three experiments, significant regressions exist between $H$. serrata larval density and a range of yield parameters, including the total number of pods recovered per micro-plot, and the number of white-grub damaged pods (table 3). In all cases, regressions were at least highly significant $(\mathrm{P}<0.01)$. For H. serrata, the rate of reduction in total pod numbers (average 11.23 pods/ larva) is approximately an order of magnitude greater than the rate of increase in the number of white grub damaged pods (average 1.08 damaged pods/larva). The explanation for this result lies in the observations made during the 1999 harvest that grubs consumed almost all of an attacked pod when feeding. Remnants of such pods would quickly disappear, resulting in a reduction in pod number rather than an increase in damaged pods, given that the concurrent root 
damage reduced the plant's capacity to replace damaged pods by producing more flowers.

Under the relatively favourable conditions existing in the 1999 experiments, there was no relationship between grub density and plant mortality $(\mathrm{P}>0.05)$. However, this association was significant $(\mathrm{P}<0.01)$ in the lower-yielding 2000 experiment.

Observations made during the 1999 sampling to assess larval establishment suggest that the grubs were feeding preferentially on the developing pods, as opposed to the roots; this would result in the lack of association between larval density and plant death in 1999.

\section{Discussion}

\subsection{Heteronyx piceus}

In this group of experiments, responses with respect to larval density are different for the two aspects of damage, i.e. holed pods and crop yield, with sites with similar regression line slopes for holed pods showing different yield responses. For example, Sites 5 and 6 showed similar slopes for the holed pods relationship but differed greatly in the rate of yield loss. This is not unexpected, because these two damage measures are quantifying different aspects of the insect/ plant relationship. The holed pods data is quantifying an important component of the feeding damage done by the H. piceus larvae, while the crop yield data is integrating the plant's overall response to this feeding. The insect and the plant will, most likely, be responding to different aspects of the environment, resulting in the different relationships across the experimental sites. 
Insecticide is not currently used by growers against $H$. piceus, so calculation of a provisional economic injury level is based on the most likely product to be registered, namely imidacloprid seed dressing $(0.625-1.25 \mathrm{~g}$ a.c. $/ \mathrm{kg}$ seed $)$ at a cost in the vicinity of $\$ 50 / \mathrm{ha}$. This provides protection for the 6 - 8 weeks after planting when the crop is being infested. Dryland groundnut grown in the South Burnett are typically worth approximately $\$ A 650 /$ tonne. On this basis, the expected cost of an imidacloprid seed dressing is equivalent to the value of $77 \mathrm{~kg}$ of nuts. This equates to the crop loss from $H$. piceus densities of 1.7 and 4.9 larvae/ row-metre in crops yielding less and more than $1900 \mathrm{~kg} / \mathrm{ha}$, respectively.

The practical difficulty of implementing these economic injury levels is that the treatment of choice has to be applied at planting (Rogers and Brier, 1992) before either crop yield potential or pest pressure is known. However, these indicative thresholds can still guide white grub management decisions because population dynamics studies (Ward and Rogers, in press) have shown that landscape position strongly impacts on the H. piceus infestation risk. Specifically, there is a 5\% probability that end-of-season larval populations will exceed 4 larvae/ row-m in the lower half of the landscape, but $25 \%$ that it will exceed this level in the upper half of the landscape. On plateaus and hillcrests, one-quarter of crops have populations greater than 8 larvae/ row-m. Knowledge of the landscape-based infestation risk of an individual field can be combined with information on the field's fertility-related yield potential and southernoscillation-index based seasonal rainfall forecasts to reach a decision on the need for insecticide treatment of planting seed. 
The district-wide crop loss estimates based on these damage potential estimates indicate that in a poor season, the direct crop losses from H. piceus total 1264 tonnes of groundnuts worth $\$ 0.82 \mathrm{~m}$ across approximately 11,000 ha of dryland groundnuts normally grown in the South Burnett region. Estimated district-wide losses are lower in better seasons, as a greater proportion of the crop is in the yield zone where crop compensation is apparently greater. Wright (1997) estimated that in a typical decade, growers would experience 3 good years, 4 average years and 3 bad years in terms of yield expectations; the long-term average loss based on this pattern of seasons is 873 tonnes per year, worth $\$ 0.57 \mathrm{~m}$.

\subsection{Holotrichia serrata}

The increase in plant deaths from $H$. serrata feeding in the 2000 experiment has been recorded in studies done with $H$. serrata in 1994 (J. Wightman, unpublished data), and regularly observed in farmers' fields (Anitha et al., in press). It appears that plant loss from $H$. serrata attack occurs under some circumstances but not others, with the favourability of the growing conditions for the crop perhaps being an important determinant of whether plant death occurs. This is consistent with the results of the damage-simulation studies of Wightman et al. (1994) that showed that moisture stress markedly reduced the groundnut plant's capacity to recover from root pruning.

The determination of how much yield loss can be attributed to each grub allows a provisional economic injury level to be developed. Chemical control of white grubs using chlorpyrifos at the recommended rate of $1.2 \mathrm{~g}$ a.i./ $\mathrm{kg}$ of seed $(6 \mathrm{~mL}$ of $200 \mathrm{~g} / \mathrm{L}$ e.c.) (Anitha et al. in press) costs approximately Rs $1 / \mathrm{kg}$ of seed, or Rs $100-120$ per 
ha. If the return to farmers from groundnut is approximately $\mathrm{Rs} 11 / \mathrm{kg}$, then the rate of yield loss recorded for $H$. serrata in our experiments indicate that the cost of control for white grubs is equivalent to the loss from approximately one grub every $7.1 \mathrm{~m}^{2}$. In field surveys conducted in southern India (Anitha et al. in press), more than $70 \%$ of the 93 fields surveyed had larval populations exceeding 1 Holotrichia species larva/ 15 samples, i.e. greater than 1 grub/ $1.35 \mathrm{~m}^{2}$. Anitha et al. (in press) also show that white grub infestation is a recurrent problem on individual farms in south-central India. This suggests that white grubs are a serious and persistent source of economic loss for groundnut farmers in southern India. On this basis, farms that have a history of white grub damage to groundnut should routinely apply seed treatments for white grub control at planting, on the basis that there is a high probability that end-of-season larval populations will exceed the economic injury level by a wide margin.

\subsection{General discussion}

Both species of white grub studied here reduce the yield of the groundnut plant. However, they do so via different effects on the number of total pods and damaged pods; these differences reflect the biologies of the two species. H. serrata attacks both pods and roots, reducing plant vigour, inducing moisture stress and if damage is severe, killing plants. In contrast, $H$. piceus does not cause overt root damage and any plant stress symptoms, but concentrates its feeding on the developing pods; crops that are heavily infested by $H$. piceus show no signs of moisture stress or plant death. In addition, the smaller size of $H$. piceus larvae (maximum size $0.275 \mathrm{~g}$ ) compared to $H$. serrata (maximum size $3.5 \mathrm{~g}$ ), means that attacked pods are not entirely consumed, but rather the shell, and possibly one kernel (of the two typically in a pod), is left. By 
comparison, $H$. serrata almost entirely consumes pods, as well as damaging roots producing plant stress and death. The end result of these differences is that normally $H$. piceus does not reduce total pod numbers, while $H$. serrata does.

These differing biologies result in the two species having markedly different damage potentials/ $\mathrm{g}$ of fresh weight. For $H$. piceus, the loss is $16.3 \mathrm{~g}$ and $5.2 \mathrm{~g}$ of crop yield per $\mathrm{g}$ of larval fresh weight (for crops yielding less and more than $1900 \mathrm{~kg} / \mathrm{ha}$, respectively), and $3.2 \mathrm{~g}$ per $\mathrm{g}$ of fresh weight for H. serrata.

The reasons underlying these markedly different damage potentials appears to lie in the relative phenologies of the pest and crop for the two species. For H. piceus, the third instar larval population peaks in March - April, and larvae reach maximum size at about the same time as the crop matures (Ward \& Rogers, in press). That is, maximum feeding occurs close to crop maturity when there is little potential for compensation by the crop. In contrast, $H$. serrata larvae grow very rapidly, reaching maximum weight $(3.5 \mathrm{~g})$ within 44 days of being introduced at 18 d.a.s to microplots as early second instars $(0.2 \mathrm{~g})$ (John Wightman, unpublished data). Larval weight at crop maturity (3.2 g), a further 62 days later, indicated that little or no additional growth had occurred. Thus, for H. serrata there is a period of approximately 60 days between when the larvae reach maximum size (and presumably finish active feeding) and crop maturity. This provides time for the plant to, at least partially, compensate for $H$. serrata feeding. This, in turn, leads to the lower damage potential of $H$. serrata compared to $H$. piceus, when these species are compared in terms of yield loss per gram of insect fresh weight. 


\section{Acknowledgments}

Mr Hugh Brier, Queensland Department of Primary Industries, provided access to the original data from his carbofuran screening trials re-analysed here. We would like to thank Md Khaja, Manaiah, Ravindra Babu, Anjaneyulu and Babu Rao for their technical assistance with the conduct of the work at ICRISAT. Dr G V Ranga Rao and his team of the IFAD IPM project at ICRISAT also deserve our thanks for their cooperation during the trials. Funds for this work were provided by the Australian Centre for International Agricultural Research as part of project CS2/94/50 "Management of white grubs in peanut cropping systems in Asia and Australia”.

\section{References}

Anitha, V., Rogers, D.J. Wightman, J., and Ward, A. In press. Distribution and abundance of white grubs (Coleoptera: Scarabaeidae) on groundnut in southern India. Crop Protection.

Brier, H.B. 1989. Control of the peanut scarab Heteronyx piceus in peanuts. In L.N. Robertson \& P.G. Allsopp (eds.) Proceedings of Soil Invertebrates Workshop, Brisbane. QDPI Conference and Workshop Series QC89004, Brisbane Australia, pp. $91-94$

Crosthwaite, I. 1994. Peanut Growing in Australia. Queensland Department of Primary Industries Information Series Q194019. QDPI, Brisbane. 93pp.

Rogers, D.J. \& Brier H.B. 1992. Application methods for granular insecticides to control Heteronyx piceus Blanchard (Coleoptera: Scarabaeidae) larvae in peanuts in Queensland. Plant Protection Quarterly 7, 48 - 50. 
Ward, A.L. and Rogers D.J. in press. Population dynamics of Heteronyx piceus (Coleoptera: Scarabaeideae) in a peanut/ maize cropping system. Bulletin of Entomological Research.

Wightman, J.A., Brier, H.B. and Wright, G.C. 1994. The effect of root damage caused by simulated white grub attack on the growth, yield and water-use of groundnut plants. Plant and Soil, 160, $267-275$.

Wightman, J.A. and Ranga Rao G.V. 1994. Groundnut Pests. In J. Smartt (ed.) The Groundnut Crop: a scientific basis for improvement. (London, Chapman and Hall), pp. 395-469.

Wightman, J.A. and Wightman, A. S. 1994. An insect, agronomic and sociological survey of groundnut fields in southern Africa. Agriculture Ecosystems and Environment, 51, 311 - 331 .

Wright, G. 1997. Management of drought in peanuts - can crop modelling assist in long-term planning decisions. In B. Fleming, A. Cruickshank, and S. Cruickshank (eds.) Handbook and Proceedings of $2^{\text {nd }}$ Australian Peanut Conference: Quality Peanuts for Profit. July 1997, Broadbeach, Queensland. pp. 26 - 29.

Yadava, C.P.S. and Sharma, G.K., 1995. Indian white grubs and their management. All India Coordinated Research Project on Whitegrubs, Technical Bulletin No 2, Indian Council of Agricultural Research. 
Table 1: Experimental details for Holotrichia serrata microplot experiments conducted at ICRISAT Asia Centre, India 1999 and 2000.

\begin{tabular}{|c|c|c|c|c|c|c|c|}
\hline Year & Sowing Date & $\begin{array}{l}\text { Infestation } \\
\text { Date } \\
\text { (d.a.s.*) }\end{array}$ & $\begin{array}{l}\text { Larval-sSurvival } \\
\text { Sampling Date } \\
\text { (d.a.s.*) }\end{array}$ & $\begin{array}{l}\text { Crop -yield } \\
\text { Harvest Date } \\
\text { (d.a.s.*) }\end{array}$ & $\begin{array}{l}\text { Infestation } \\
\text { Period } \\
\text { (days) }\end{array}$ & $\begin{array}{l}\text { Plant Density } \\
\text { (plants/ plot) }\end{array}$ & $\begin{array}{c}\text { Treatments (larvae/ plot) } \\
\text { and Replications }\end{array}$ \\
\hline 1999 & 23/6/1999 & $\begin{array}{l}35 \\
55\end{array}$ & $\begin{array}{l}68 \\
89\end{array}$ & $\begin{array}{l}110 \\
110\end{array}$ & $\begin{array}{l}75 \\
55\end{array}$ & 30 & $\begin{array}{l}0,10,20 \\
6 \text { reps/ date, } 3 \text { for larval } \\
\text { survival, } 3 \text { for crop yield }\end{array}$ \\
\hline 2000 & $30 / 5 / 2000$ & 27 & 48 & 118 & 91 & 30 & $\begin{array}{l}0,5,10,20 \\
12 \text { reps, } 4 \text { for larval } \\
\text { survival, } 8 \text { for crop yield }\end{array}$ \\
\hline
\end{tabular}

\footnotetext{
* d.a.s. = days after sowing
} 
Table 2: Linear regression analyses between Heteronyx piceus density at crop maturity and groundnut pod numbers for seven experimental sites $(1984-1988)$ in the South Burnett region.

\begin{tabular}{lccccc}
\hline Experiment & \multicolumn{2}{c}{ Holed pods/ row metre } & & \multicolumn{2}{c}{ Total Pods/ row-metre } \\
\cline { 2 - 3 } \cline { 5 - 5 } and Year & Intercept & Slope & & Intercept & Slope \\
\hline $1(1984 / 85)$ & -0.01 & $1.6348 * * *$ & & 272.63 & $0.218 \mathrm{NS}$ \\
$2(1985 / 86)$ & 0.06 & $1.8768 * * *$ & & 176.63 & $-0.506 \mathrm{NS}$ \\
$3(1985 / 86)$ & 1.11 & $1.6508 * * *$ & & 151.74 & $2.138 \mathrm{NS}$ \\
$4(1985 / 86)$ & 0.91 & $1.5988 * * *$ & & 145.23 & $-2.362 \mathrm{NS}$ \\
$5(1986 / 87)$ & 2.43 & $3.2658 * * *$ & & 176.83 & $0.478 \mathrm{NS}$ \\
$6(1986 / 87)$ & -0.61 & $2.9818 * * *$ & & 275.43 & $-2.642 \mathrm{NS}$ \\
$7(1987 / 88)$ & 0.43 & $1.1618 * * *$ & 139.73 & $-1.675 * *$ \\
\hline
\end{tabular}

The significance of the regression lines is shown in the Slope column for each variable. $\mathrm{NS}=\mathrm{P}>0.05, * *=\mathrm{P}<0.01, * * *=\mathrm{P}<0.001$. 
Table 3: Linear regressions between the number of Holotrichia serrata larvae/ microplot at harvest and the number of mature pods and white grub damaged pods.

\begin{tabular}{lcccc}
\hline Planting and & \multicolumn{2}{c}{ Mature pods/ plot } & & Damaged pods/ plot ${ }^{1}$ \\
\cline { 2 - 3 } Infestation Date & Intercept & Slope & & Slope \\
\hline $23 / 6 / 1999,35$ DAS & $331.4^{* * * *}$ & $-15.79^{* * * *}$ & & $1.216^{* * *}$ \\
$23 / 6 / 1999,55$ DAS & $312.0^{* * * *}$ & $-8.89 * *$ & $1.556^{* * *}$ \\
$23 / 6 / 1999$, Combined & $318.0^{* * * *}$ & & $1.418^{* * *}$ \\
$30 / 5 / 2000,27$ DAS & $176.4^{* * *}$ & $-11.41^{* * *}$ & & $0.739^{* * *}$ \\
\hline
\end{tabular}

${ }^{\mathrm{I}}$ Regression through origin. ${ }^{* *}=\mathrm{P}<0.01, * * *=\mathrm{P}<0.001$. 
Figure 1: Relationships between crop yield and Heteronyx piceus density in peanuts in the South Burnett region of Queensland.
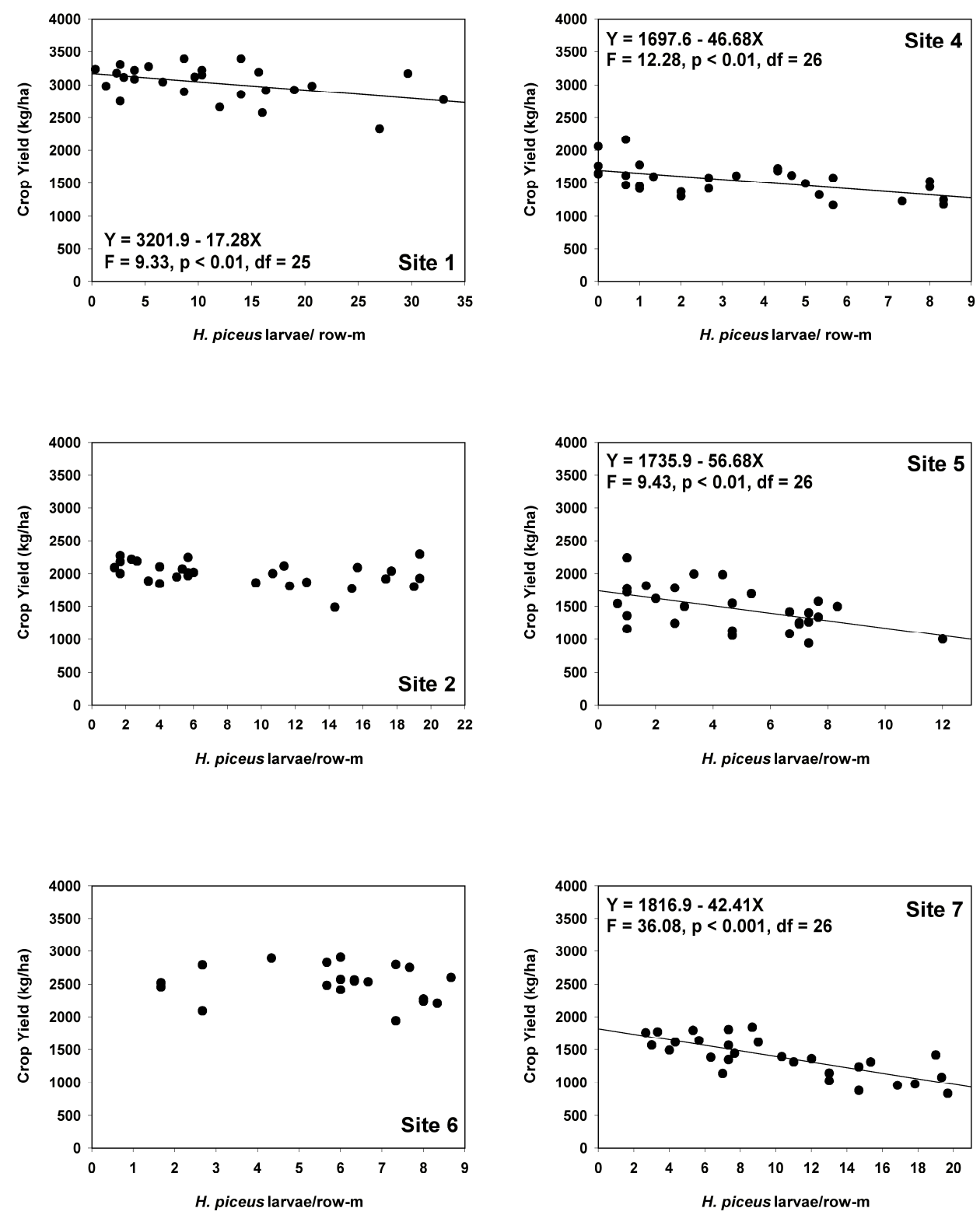
Figure 2: Plot of yield-loss regression line slope (with standard error) against peanut crop yield for six sites infested with Heteronyx piceus in the South Burnett region of Queensland.

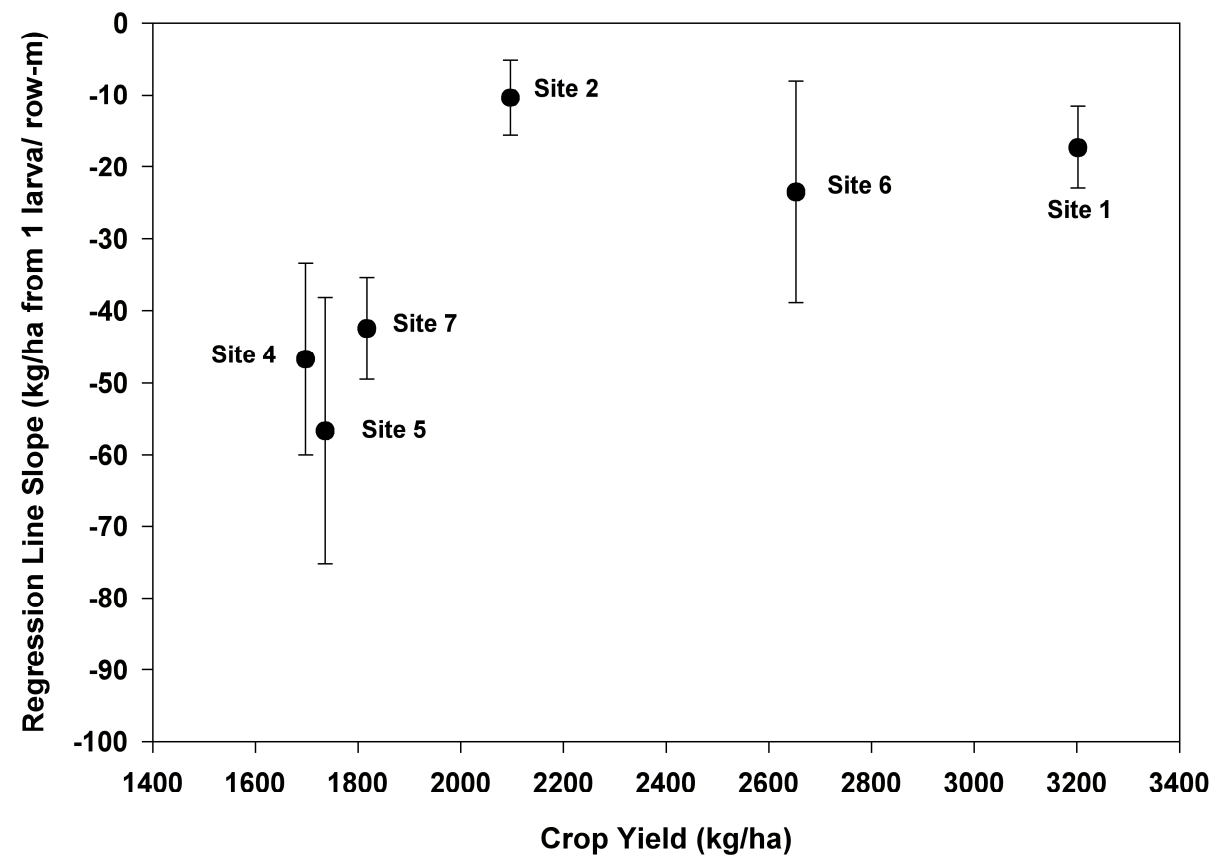


Figure 3: Relationship between groundnut yield and number of Holotrichia serrata in microplots, (A) planted 23/6/1999, infested 35 DAS (B) planted 23/6/1999, infested 55 DAS, (C) infested 30/5/2000, infested 27 DAS.
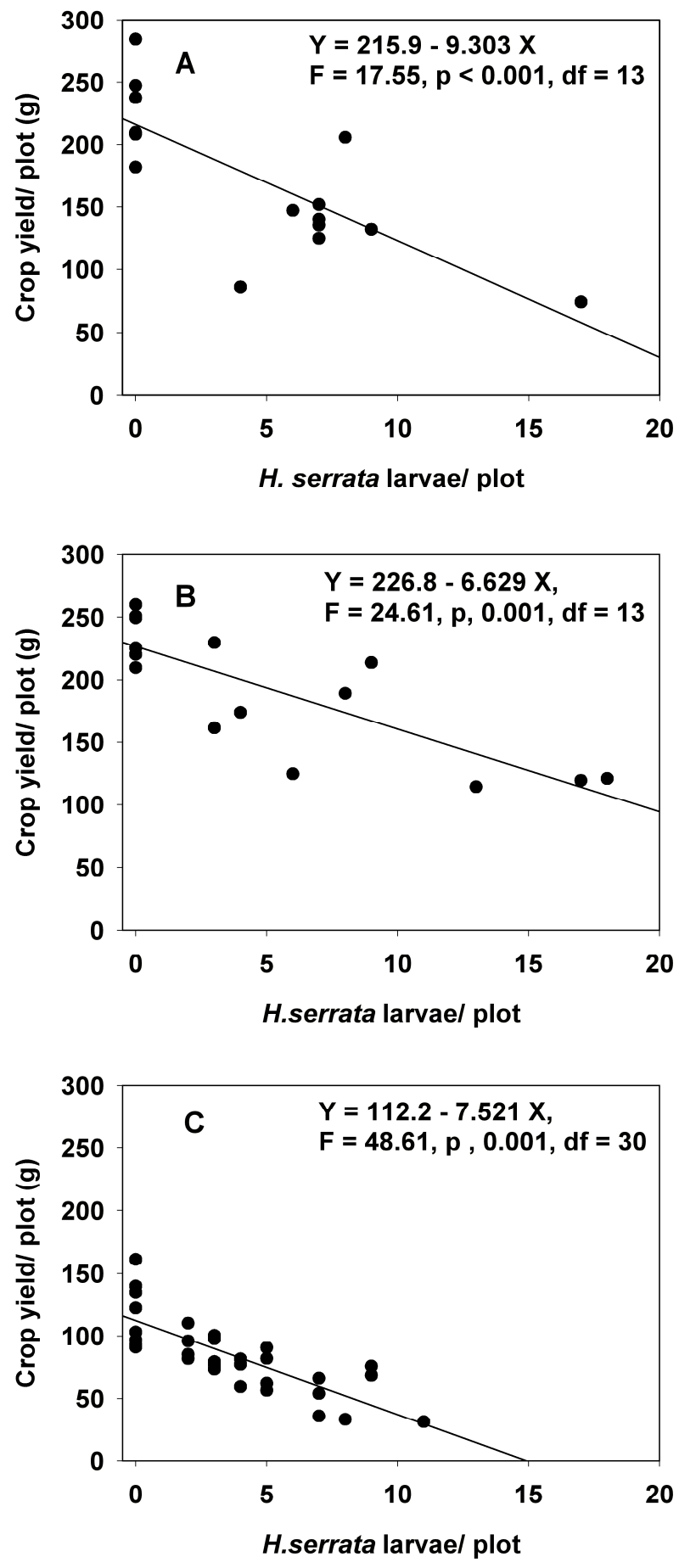